64.7

\title{
Experimental Study Of Parasitically Steered, Fixed Beam Microstrip Patch Arrays
}

D.P. Gray*, J.W. $\mathrm{Lu}^{+}$and L. Shafai*

*Dept. Of Electrical \& Computer Engineering, University Of Manitoba, Winnipeg, Canada R3T 5V6 [dgray@ee.umanitoba.ca]

${ }^{+}$School Of ME, Griffth University, Nathan, Australia 4111

\section{INTRODUCTION}

The linearly polarised single feed point Yagi microstrip patch array was developed from the concept of the thin wire Yagi-Uda array [1]. It is possible to build either vertically polarised or horizontally polarised arrays. Both feed points of an array can be excited with the correct amplitude and phasing to produce circular polarisation. A Yagi microstrip patch array produces a mainlobe away from the zenith, and has the advantage of being planar for applications such as wireless office.

The aim of this paper is to investigate the influence of various characteristics of the dielectric substrate upon array performance and to access the effects of reduction of the array size upon its behaviour. The collected experimental data will be useful for comparison to numerical simulations in future work. The linear polarised measurements were undertaken in the anechoic chamber at the University of Manitoba.

\section{DESIGN PHILOSOPHY}

All array dimensions were calculated at fixed proportions to a square patch on the given dielectric substrate, Figure 1. The same proportions were used for all the arrays to allow for comparison of factors other than the array proportions. These proportions differ slightly from those described by Huang [1]. Four arrays were built and tested for the $1.45-1.75 \mathrm{GHz}$ frequency range, and six for the 2.9$3.4 \mathrm{GHz}$ range. Three dielectric substrates were used, lexan polycarbonate $\left\langle\varepsilon_{r} \approx 2.88\right\rangle, \operatorname{TMM} 3\left\langle\varepsilon_{r}=3.27\right\rangle$ and TMM4 $\left\langle\varepsilon_{r}=4.50\right\rangle$.

The commercially available software Ensemble $4.02^{\mathrm{TM}}$ was used to determine the optimal feed positions for each of the arrays, by repeated simulations with different feed positions. The loci for the two different feed positions are indicated in Figure 1. Due to the symmetry of the array, there are two possible $\mathrm{H}$-plane feed points. There are also two possible E-plane feed points; one close to the edge of the driven patch closest to the reflector patch (as used in [1]) and the other close to the edge closest to the director patches. 


\section{EFFECTS OF USING FORWARD FEED POSITION}

As noted above, there are two possible E-plane feed positions. Using the position closest to the director patches significantly reduces the cross-polar level, without changing the co-polar pattern, Figure 2 . The $S_{11}$ traces from two arrays that were identical in all ways except the positioning of the E-plane feed shows that the $\mathrm{H}$-plane feed $\mathrm{S}_{11}$ were very similar as was expected, Figure 3.

\section{EFFECTS OF REFLECTOR PATCH REMOVAL}

Removal of the reflector patch would allow for a reduction in the overall size of the array. Removing the reflector patch entirely, or replacing it with a printed dipole, caused a decrease in the co-polar backlobe and an increase in the cross-polar level for higher elevations, Figure 4. This shows that the reflector patch may be removed to reduce the array size without significant degradation of performance.

\section{EFFECTS OF GROUND PLANE SIZE INCREASE}

Some applications of this type of planar array will require mounting above an extended ground plane. It has been found that the ground plane size is critical to the performance of microstrip patch antennas [2]. An addition of a $0.9 \times 0.9 \mathrm{~m}$ ground plane caused the gain at low elevations to increase, Figure 5.

\section{EFFECTS OF DIFFERENT SUBSTRATE THICKNESSES}

A number of dielectric substrate thicknesses were trialed in order to gain insight into the effects of the thickness upon array performance. Increasing the substrate thickness from 3.10 to $5.90 \mathrm{~mm}$ caused a decrease in mainlobe gain and increases in the backlobe and cross-polar levels, Figure 6.

\section{EFFECTS OF DIFFERENT DIELECTRIC CONSTANTS}

For the arrays constructed on TMM3 and TMM4, the electrical thickness of the dielectric substrates was just over $7 \%$ of the dielectric wavelength. Increasing the relative permittivity ( 3.27 to 4.50 ) caused an increase in mainlobe gain and decreases in backlobe and cross-polar levels, Figure 7.

\section{REFERENCES}

[1] J. Huang, "Planar Microstrip Yagi Array Antenna", IEEE AP-S Symposium, June 1989, pp894-897, San Jose, CA.

[2] S. Noghanian \& L. Shafai, "Effects of Finite Ground Plane and Substrate Dimensions on the Radiation Pattern of a Circular Microstrip Antenna", ANTEM 1996 Conference, pp383-386, August 1996, Montreal. 


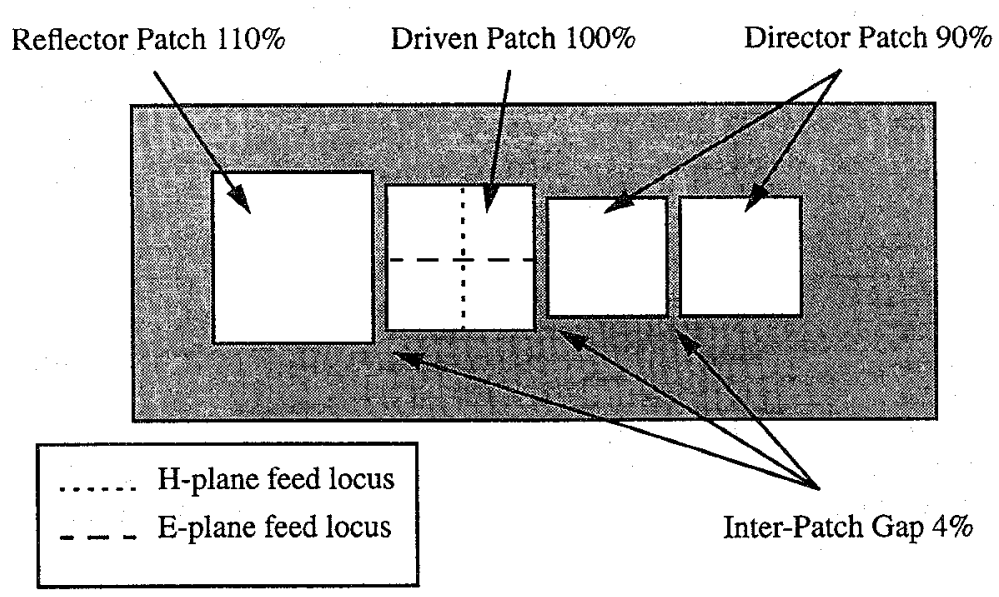

Figure 1: Geometry of Yagi microstrip patch array with array element dimensions as percentages of square patch size marked.

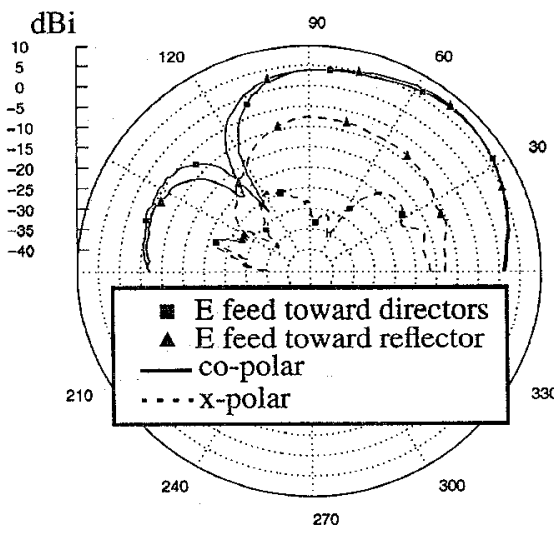

Figure 2: Radiation patterns from the 2 possible E-plane feed points at $1.55 \mathrm{GHz}$ from the $5.90 \mathrm{~mm}$ lexan substrate arrays.

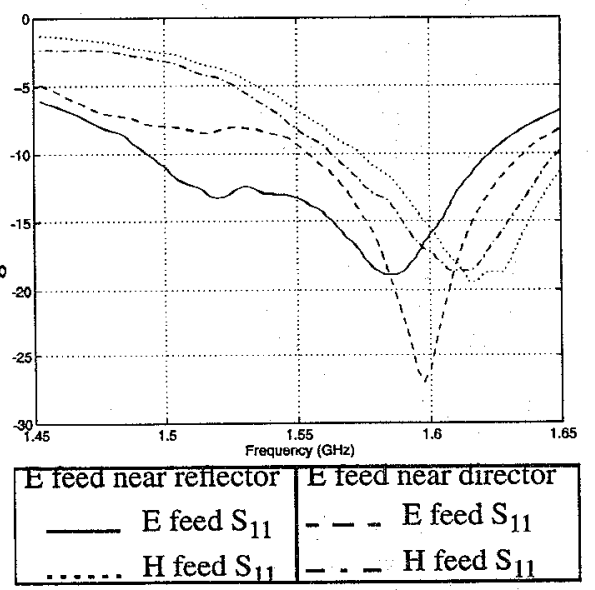

Figure 3: $S_{11}$ in $d B$ from the 2 possible E-plane feed points from the $5.90 \mathrm{~mm}$ lexan substrate arrays. 


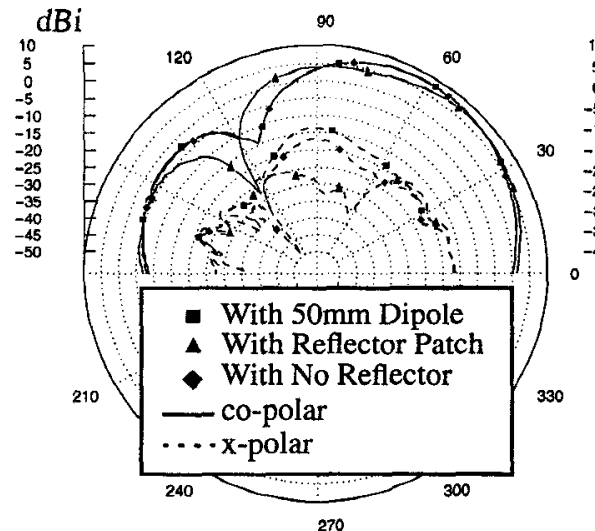

Figure 4: Radiation patterns without the reflector patch from the $5.90 \mathrm{~mm}$ lexan substrate array with E-plane feed toward the director patches at $1.55 \mathrm{GHz}$.

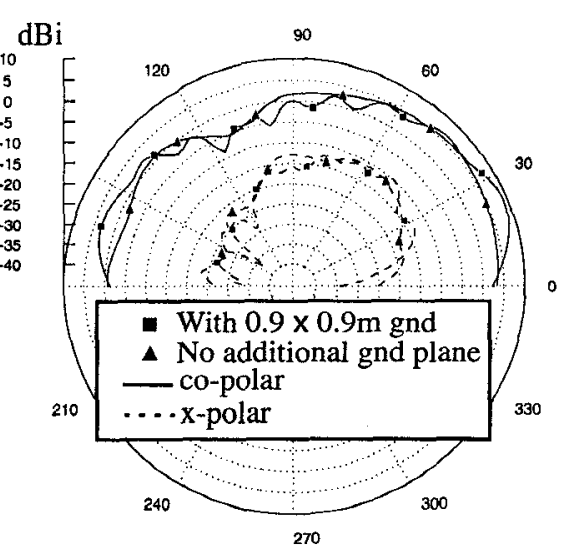

Figure 5: Radiation patterns for the addition of $0.9 \times 0.9 \mathrm{~m}$ ground plane from the TMM3 array with E-plane feed toward the director patches at $3.06 \mathrm{GHz}$.

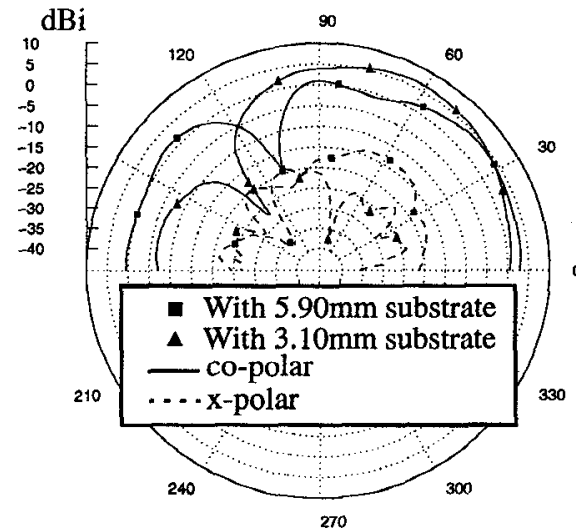

Figure 6: Radiation patterns for different thickness lexan substrates from the arrays with E-plane feeds toward the director patches at $3.06 \mathrm{GHz}$.

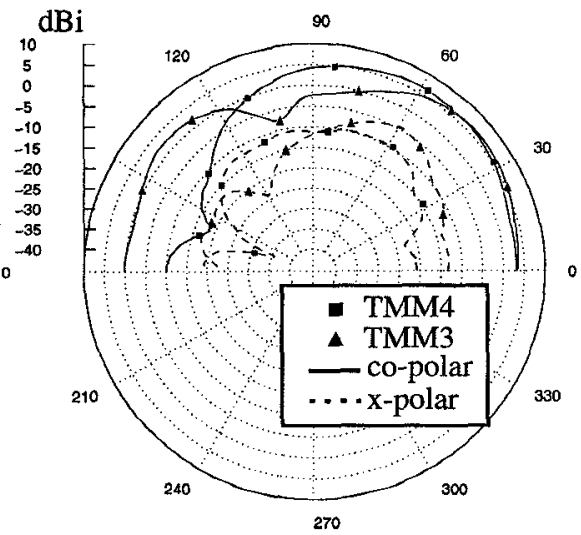

Figure 7: Radiation patterns for different relative permittivity substrates having the same electrical thickness from the arrays with E-plane feeds toward the reflector patch at $3.1 \mathrm{GHz}$. 